Review

\title{
Telomerase as a tumor-associated antigen for cancer immunotherapy
}

\author{
Kunal P. Patel and Robert H. Vonderheide* \\ Abramson Family Cancer Research Institute, University of Pennsylvania, Philadelphia, PA 19104, USA; \\ *Author for correspondence (e-mail: rhv@mail.med.upenn.edu; phone: +1-215-573-4265; fax: +1-215-573- \\ 2652)
}

Received 24 May 2004; accepted in revised form 21 September 2004

Key words: Cryptic epitope, Telomerase, T-lymphocyte, Tumor antigen, Vaccine

\begin{abstract}
Telomerase reverse transcriptase hTERT is an attractive target for cancer immunotherapy given its broad expression in human tumors and its demonstrated immunogenicity. Human and murine model systems demonstrate that $\mathrm{CD} 8^{+}$cytotoxic T-lymphocytes $(\mathrm{CTL})$ and $\mathrm{CD} 4^{+}$helper T-lymphocytes can recognize dominant epitopes derived from TERT. CTL kill TERT-positive tumor cells of multiple histologies, although there is some disagreement regarding the level of processing and presentation of certain TERT peptides within the context of MHC class I molecules. CTL recognizing modified, low-affinity cryptic TERT epitopes have also been generated that protect against tumor challenge in a murine model. Several phase I clinical trials testing hTERT as a cancer vaccine target have shown the induction of T-cell immune responses but minimal toxicities, including bone marrow toxicity, in patients with multiple types of cancer. Several studies report some patients experiencing clinical benefit, including partial tumor regression, providing further encouragement for hTERT as broadly applicable target for cancer immunotherapy.
\end{abstract}

Abbreviations: CTL - cytotoxic T-lymphocyte; DC - dendritic cells; HLA - human leukocyte antigen; LAMP - lysosome associated membrane protein; MHC - major histocompatibility complex; TAA tumor-associated antigen.

\section{Introduction}

Experimental data from the past 10 years have demonstrated that tumor-associated antigens (TAA) can cause highly specific T-lymphocyte responses against cancer cells while sparing normal cells. These observations form the rationale behind the use of hTERT (human telomerase reverse transcriptase) as a potential antigen for cancer immunotherapy. The original TAA were discovered in the early 1990s from the analysis of tumor infiltrating T-lymphocytes in melanoma patients (Van Pel et al. 1995; Rosenberg 1997). Numerous TAA from a variety of malignancies have now been identified, suggesting that all cancers possess associated antigens that can be used to direct a specific anti-tumor T-lymphocyte response (Van Pel et al. 1995; Rosenberg 1997, 2001; Van den Eynde and van der Bruggen 1997). Animal models have provided further validation (Gilboa 1999) that these TAA can function as tumor rejection antigens in vivo.

CD8 ${ }^{+}$cytotoxic T-lymphocytes (CTL) have been studied as the chief effector cell of the antigen-specific lymphocyte immune response (Van Pel et al. 1995; Van den Eynde and van der Bruggen 1997). Antigen receptors on the surface of 
CTL recognize 9-10 amino acid peptides presented on the surface of tumor cells in the context of major histocompatability complex (MHC) class I molecules. Specific recognition of peptide/MHC complexes by CTL antigen receptor leads to a T-cell response of cytokine secretion and eventual target cell lysis. Proteosomal digestion of intracytoplasmic proteins, which may or may not be destined for the cell surface, generates peptide epitopes presented by MHC I molecules. Tumor antigens discovered to date are largely intracytoplasmic self-antigens that are either overexpressed or selectively expressed by tumor cells.

\section{Problem of universal antigens}

While the concept of TAA was a significant scientific breakthrough, the problem of discovering antigens that can be widely applied to various malignancies, i.e. universal TAA, has been a limitation. A factor contributing to the limited characterization of universal tumor expression has been the method of antigen discovery commonly employed. The classical approach relies upon the isolation of tumor infiltrating lymphocytes and determining antigens these CTL react against. Such methodology limits researchers to search malignancy-by-malignancy for antigens and only for tumors for which tumor infiltrating lymphocytes can be isolated. The hTERT peptides were discovered using a method of epitope deduction. Our group analyzed genes that were selectively expressed by a variety of tumor cells, and then analyzed those applicable gene products to deduce protein sequences for peptides that match known MHC binding motifs (reviewed in Schultze and Vonderheide 2001). This method does not rely upon the presence of an anti-tumor response, therefore allowing the discovery of antigens that classical analysis could never find. Validation of these deduced epitopes occur via a series of immunological studies that have been previously reviewed (Schultze and Vonderheide 2001).

\section{The case for hTERT as a universal antigen - selective expression and auto-immunity}

Criteria for universal TAA include: (i) expression by the vast majority of human cancers, (ii) pres- ence of peptides that bind to MHC molecules, (iii) sufficient natural antigen processing by tumor cells that leads to expression of antigen-derived peptides in the groove of MHC, and (iv) recognition by T-cell repertoire in an MHC-restricted fashion. Data from the past 5 years suggest that telomerase catalytic subunit hTERT meets these criteria.

Expression of hTERT correlates best with telomerase activity, suggesting that the catalytic subunit functions as the rate-limiting component of telomerase (Harrington et al. 1997; Meyerson et al. 1997; Nakamura et al. 1997; Bodnar et al. 1998; Counter et al. 1998; Vaziri and Benchimol 1998). Telomerase maintains the telomeric ends of linear chromosomes, protecting them from degradation and end-to-end fusion (Harley et al. 1994). Expression of telomerase has been directly linked to human cancer development (Hahn et al. 1999a), and without telomerase activity, cancer cells are thought to be unable to replicate beyond the limits of normal cells leading to eventual death. Therefore, even with the selective pressure of immunotherapy, malignancies should not be able to clonally select for hTERT negative cells and still maintain their prolonged cell life span. Work in cell culture demonstrates that inhibition of telomerase in telomerase-positive cells leads to tumor death without the emergence of telomerase-negative cells (Hahn et al. 1999b; Herbert et al. 1999; Zhang et al. 1999). While not an explicit criterion for universal antigens, prevention of immune escape adds to the value of hTERT as a target for immunotherapy.

Most human cells do not have telomerase activity or hTERT expression (Kim et al. 1994; Meyerson et al. 1997; Nakamura et al. 1997), while the great majority of human tumor cells ( $>85 \%$ of human cancers) exhibit strong telomerase activity (Kim et al. 1994), express hTERT (Meyerson et al. 1997; Nakamura et al. 1997; Ramakrishnan et al. 1998), and maintain the length of their telomeres (Counter et al. 1992, 1994). Normal cells that do possess telomerase activity include $\mathrm{CD} 34^{+}$hematopoietic progenitor cells (Broccoli et al. 1995; Hiyama et al. 1995), keratinocytes (Harle-Bachor and Boukamp 1996; Yasumoto et al. 1996), and activated B-lymphocytes (Vonderheide et al. 1999). Recently, primary presenescent human fibroblasts have been shown to express telomerase (Masutomi et al. 2003), a surprising finding given that fibroblasts were previously thought to lack 
any telomerase activity. The presence of hTERT in some normal cells, particularly hematopoietic progenitor cells and B-cells, raises serious questions of potential auto-immune side effects of hTERT-based cancer immunotherapy. However, all experimental results to date illustrate that hTERT-specific CTL do not lyse either telomerase-positive $\mathrm{CD} 34^{+}$hematopoeitic progenitor cells - with or without cytokine activation - or activated T-lymphocytes (Vonderheide et al. 1999, 2001a; Minev et al. 2000). Activated B-lymphocytes are the only cell type other than tumor cells that have shown an in vitro susceptibility to hTERT-specific CTL mediated lysis (Vonderheide et al. 1999). The mechanisms by which CD $34^{+}$ progenitor cells avoid while B-cells are prone to lysis have yet to be elucidated. Variety in antigen processing and different levels of hTERT expression are two leading hypotheses.

\section{Processing, presentation, and recognition - the ongoing debate}

Tumor cells physiologically express peptides in the groove of MHC class I molecules on the cell surface (a process known as natural processing and presentation), where they can be recognized by CTL induced, for example, by vaccination with these same peptides. This trio - processing, presentation, and recognition - represent three significant criteria that a TAA must meet in order to be effective. Several peptides derived from hTERT are thought to be naturally processed by tumor cells, presented in an MHC class I-restricted fashion, and serve as a target for antigen-specific CTL (Vonderheide et al. 1999) (Table 1). The first hTERT peptide described, I540 (ILAKFLHWL), is a dominant epitope found within the middle of the deduced amino acid sequence of hTERT, approximately 70 amino acids to the amino terminus of the first reverse transcriptase motif. Discovered via epitope deduction, I540 is restricted to the MHC class I allele human leukocyte antigen (HLA)-A*0201 (HLA-A2), which is the most frequently expressed $\mathrm{MHC}$ class I allele (found among nearly 50\% of Caucasians, Asians, and Hispanics as well as $33 \%$ of African-Americans). The peptide has been shown experimentally to bind strongly to HLA-A2 and generate from $>70 \%$ of individuals CTL specific for I540 peptide that are able to kill hTERT-positive tumor cell lines and primary tumors from a wide variety of malignancies in a peptide-specific, MHC-restricted fashion (Vonderheide et al. 1999). In addition to I540, other dominant hTERT-derived CTL epitopes that are restricted to other common MHC class I alleles have been described. The peptide K973 (KLFGVLRLK) binds strongly to HLA-A3 and triggers MHC-restricted CTL lysis of hTERT-positive tumors from a range of histologies (Vonderheide et al. 2001b). Peptides restricted to HLA-A24 have also been identified (Arai et al. 2001).

Natural processing and presentation of I540 is suggested based on the cytolysis of the HLA-A2 ${ }^{+}$, telomerase-negative sarcoma cell line U2OS only after retroviral infection with full-length hTERT but not vector alone. Monoclonal antibodies against HLA-A2 blocked cytolysis of hTERTinfected U2OS by CTL (Vonderheide et al. 1999). Analysis via tetrameric complexes of MHC class I and peptide in flow cytometry identified a $1-3 \%$ population of tetramer-positive $\mathrm{CD} 8{ }^{+}$cells among ex vivo expanded CTL (Vonderheide et al. 2001a). Ayyoub et al. demonstrated with tetramers that monoclonal and polyclonal $\mathrm{CD}^{+} \mathrm{CTL}$ could readily be detected after $\mathrm{PBMC}$ were stimulated

Table 1. hTERT-derived $\mathrm{CD} 8^{+}$and $\mathrm{CD} 4{ }^{+}$T-cell epitopes.

\begin{tabular}{|c|c|c|}
\hline Epitope & Sequence & $\begin{array}{l}\text { Restriction } \\
\text { element }\end{array}$ \\
\hline \multicolumn{3}{|c|}{ Dominant CTL epitopes } \\
\hline $\mathrm{I} 540^{\mathrm{a}}$ & ILAKFLHWL & $-\mathrm{A} 2$ \\
\hline $\mathrm{R} 865^{\mathrm{b}}$ & RLVDDFLLV & $-\mathrm{A} 2$ \\
\hline K973 & KLFGVLRLK & $-\mathrm{A} 3$ \\
\hline $\mathrm{V} 324^{\mathrm{d}}$ & VYAETKHFL & $-\mathrm{A} 24$ \\
\hline $\mathrm{V} 461^{\mathrm{d}}$ & VYGFVRACL & $-\mathrm{A} 24$ \\
\hline \multicolumn{3}{|c|}{ Dominant $\mathrm{CD}^{+}{ }^{+}$epitopes } \\
\hline $\mathrm{L} 766^{\mathrm{e}}$ & LTDLQPYMRQFVAHL & $\begin{array}{l}\text {-DR4, -DR11, } \\
\text {-DR15 }\end{array}$ \\
\hline $\mathrm{R} 672^{\mathrm{f}}$ & RPGLLGASVLGLDDI & $\begin{array}{l}\text {-DR1, -DR7, } \\
\text {-DR15 }\end{array}$ \\
\hline \multicolumn{3}{|c|}{ P1Y heteroclitic variant CTL epitopes } \\
\hline $\mathrm{Y}_{572^{\mathrm{g}}}$ & YLFFYRKSV & $-\mathrm{A} 2$ \\
\hline Y988 & YLQVNSLQTV & $-\mathrm{A} 2$ \\
\hline
\end{tabular}

${ }^{\mathrm{a}}$ Vonderheide et al. (1999).

b Minev et al. (2000).

${ }^{\mathrm{c}}$ Vonderheide et al. (2001b).

${ }^{\mathrm{d}}$ Arai et al. (2001).

${ }^{\mathrm{e}}$ Schroers et al. (2003).

${ }^{\mathrm{f}}$ Schroers et al. (2002).

${ }^{\mathrm{g}}$ Scardino et al. (2002). 
with I540 and these cells could recognize HLA-A2 ${ }^{+}$cells pulsed with I540 peptide or transiently transfected with the minimal epitope (Ayyoub et al. 2001). However, I540 peptide-CTL failed to recognize wild-type telomerase-positive tumor cells and in vitro proteasome digestion of hTERT failed to produce I540, suggesting ineffective antigen presentation due to improper processing of I540 (Ayyoub et al. 2001; Speiser et al. 2002). On the other hand, other groups have independently confirmed that I540-specific CTL are able to lyse hTERT-loaded target cells in a HLA-restricted, hTERT-specific manner (Minev et al. 2000). Additionally, high affinity hTERT specific antibodies were generated via a phage antibody library and shown to bind to I540 peptide expressed on the cell surface of tumor cells, providing further evidence that hTERT epitopes are being effectively processed and presented on the surface of tumor cells (Lev et al. 2002). Finally, TERT RNA-transfected dendritic cells (DC) used to vaccinate mice led to the production of CTL that could lyse melanoma and thymoma cancer cells as well as inhibit growth of three other tumors in mice of different genetic backgrounds (Nair et al. 2000).

\section{Cryptic epitopes as a means of addressing the issue of tolerance}

Most of the currently described hTERT CTL epitopes are dominant as defined by their high affinity and stable interactions with MHC class I molecules. While such interactions lead to the generation of a robust immune response, dominant epitopes can also stimulate tolerance due to their high affinity and stability. Cryptic epitopes, defined by their low affinity and unstable interactions with MHC class I molecules, have also been explored as possible hTERT-derived tumor antigens because $\mathrm{T}$-cells reactive with these epitopes may more likely escape tolerance induction. Traditionally thought of as poorly immunogenic, cryptic epitopes can induce a prominent CTL response after 'heteroclitic' modification, for example, changing position 1 to tyrosine (P1Y variants). This substitution increases binding of MHC and peptide, leading to the generation of CTL, in contrast to wild-type cryptic peptide, which fails to induce CTL. While cryptic epitopes possess low affinity and have unstable interaction with MHC molecules, properties that prevent them from being able to prime a CTL response, they are thought to be expressed at a high enough level physiologically by tumor cells to serve as target epitopes for effector CTL.

P1Y variants of naturally occurring and processed cryptic hTERT epitopes generate CTL that lyse malignant cells of various histologies in a MHC-restricted and hTERT specific manner and can be used to induce anti-tumor lymphocytes in peptide vaccinated mice (Scardino et al. 2002). In mice, a head-to-head comparison of dominant and P1Y variants of cryptic epitopes demonstrated that the latter protect mice against a lethal challenge with an mTERT-expressing tumor while high affinity and more stable dominant epitopes did not (Gross et al. 2004). The failure of dominant epitopes to protect efficiently against tumor challenge was hypothesized to be due to the selective in vivo purging of high avidity CTL from the T-lymphocyte repertoire. Therefore, CTL induced by dominant epitopes are of lower avidity. Such purging does not occur with P1Y heteroclitic variants, likely due to insufficient presentation and deletion in the thymus, and thus a stronger CTL response is generated.

While cryptic epitopes represent an area for future antigen discovery, dominant epitopes have been used both in vitro and in vivo to induce specific CTL in humans. For example, hTERT-specific CTL have been generated ex vivo from cancer patients in multiple experimental systems. CTL against hTERT were equivalently induced ex vivo from cancer patients and normal volunteers, with CTL from each donor type labeling brightly with peptide/MHC tetramers and efficiently killing hTERT-positive tumor cells in an MHC-restricted fashion (Vonderheide et al. 2001a). In another experimental approach, hTERT-specific CTL were generated ex vivo from cancer patients using autologous DC transduced with hTERT mRNA as the stimulating antigen presenting cell (Nair et al. 2000). These CTL were shown to lyse primary human tumors in an antigen-specific fashion. Finally, Vieweg and colleagues have generated polyclonal anti-tumor CTL ex vivo from patients with prostate or renal cell carcinoma following stimulation with autologous DC transduced with whole tumor mRNA (Heiser et al. 2001a, b). These CTL, as designed, had multiple antigen specifici- 
ties, a significant portion of which was against hTERT (Heiser et al. 2001a, b). These results suggest that dominant epitopes are not inducing tolerance and subsequent purging of high avidity CTL to such a degree that a strong anti-tumor CTL response cannot be generated.

\section{$\mathrm{CD4}^{+}{ }^{-}$T-cell generation}

In addition to CTL, an effective anti-tumor response is dependent upon the generation of $\mathrm{CD}^{+}$ T-lymphocytes. $\mathrm{CD}^{+}{ }^{+}$T-cells play a prominent role in generation, maintenance, and regulation of CTL response, particularly the long-term or memory response against tumors (reviewed in Hung et al. 1998). CD4 ${ }^{+}$T-cells have also been described to have direct anti-tumor effects via cytokine secretion. Recent work by Janssen et al. (2003) demonstrates that $\mathrm{CD}^{+}$cells are indispensable during the priming event of CTL, if secondary expansion against an antigen is desired. Such a long-term response would be a key component of any effective anti-tumor vaccine, and therefore the expression and discovery of $\mathrm{CD}^{+}$ epitopes from TAA is of key significance.

hTERT epitopes for $\mathrm{CD}^{+}$cells have been elucidated via epitope deduction (Table 1). Naturally processed MHC class II-restricted epitope R672 (RPGLLGASVLGLDDI) generated specific $\mathrm{CD}^{+}{ }^{+} \mathrm{T}$-cells that can respond via cytokine production to natural hTERT antigens from a variety of malignancies including prostate cancer, breast cancer, melanoma, and leukemia (Schroers et al. 2002). Additionally, no cytokine production was observed in response to autologous hTERT-positive B-cells (Schroers et al. 2002), suggesting perhaps a low potential of B-cell specific autoimmunity. More recent work has demonstrated that R672 and another described MHC class IIrestricted epitope, L766 (LTDLQPYMRQFVAHL), are promiscuous and capable of inducing $\mathrm{CD} 4{ }^{+}$response in the context of several different MHC class II types including HLA-DR1, -DR7, and -DR15 for R672 and HLA-DR4, -DR11, and -DR15 for L766 (Schroers et al. 2003). L766 is naturally processed and presented, and recognized by the T-cell repertoire in healthy people and prostate cancer patients. This peptide induces antigen-specific responses to a variety of malig- nancies and was used to vaccinate humanized HLA-DR4 transgenic mice (Schoers et al. 2003).

\section{hTERT immunotherapy clinical trials-early returns and future promise}

A number of phase I clinical trials utilizing hTERT as a TAA have been recently completed with promising results and others are ongoing. All trials had or have the primary endpoint of establishing safety of approach and dosage.

In one of the trials, completed at the Dana-Farber Cancer Institute, seven HLA-A2 ${ }^{+}$ patients with hormone-refractory metastatic prostate cancer or chemotherapy resistant metastatic breast cancer were given 34 vaccinations of autologous intermediately differentiated DC incubated ex vivo with I540 hTERT CTL dominant peptide and, as an adjuvant, keyhole limpet hemocyanin (KLH). No grade 3 or 4 adverse events were observed with an inoculating dose of $15 \times 10^{6}$ peptide-pulsed DC/vaccination except for one patient with tumor pain related to spinal cord progression one week after the first vaccine (Vonderheide et al. 2004). Due to the need for repetitive leukophoresis, escalation to the second $\left(30 \times 10^{6} \mathrm{DC} /\right.$ vaccination $)$ and third $\left(90 \times 10^{6}\right.$ $\mathrm{DC} /$ vaccination) dose levels were not performed. Because hTERT is normally expressed by CD $34^{+}$ hematopoietic progenitor cells and activated B-lymphocytes, bone marrow aspirates, serum immunoglobulin levels, and absolute B-lymphocyte counts were performed to assess potential auto-immune effects and no significant changes were observed (Vonderheide et al. 2004). hTERT specific T-lymphocytes were induced in 4 of $7 \mathrm{pa}-$ tients after multiple rounds of vaccination. Induced CTL were capable of killing tumor cells in vitro in a MHC-restricted fashion after sorting and polyclonal expansion, and partial tumor regression was observed in one patient post-vaccination that was associated with the presence of tumor infiltrating lymphocytes (Vonderheide et al. 2004), suggesting that I540 was capable of inducing an tumor-lytic immune response.

In another study ongoing at the University of Pennsylvania Abramson Cancer Center, patients with advanced breast cancer were vaccinated subcutaneously with I540 peptide emulsified in adjuvant with GM-CSF (schema in Figure 1). Among 10 patients treated thus far at the first or 


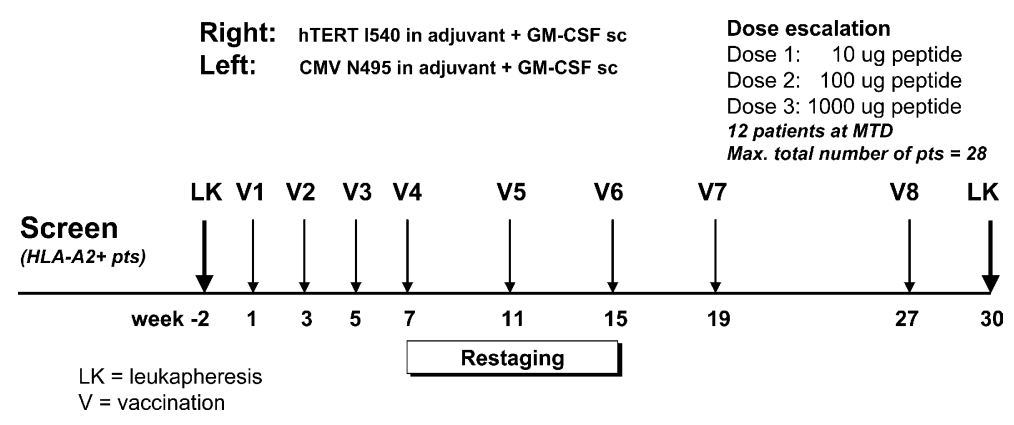

Figure 1. Clinical trial schema for telomerase vaccination of breast cancer patients at the University of Pennsylvania Cancer Center. This is an open-label, dose-escalation phase I trial for patients with advanced breast cancer to determine the safety and immunogenicity of vaccinating patients with increasing doses of hTERT peptide. Eligible HLA-A2 + patients with advanced breast cancer are injected with 10,100 , or $1000 \mu \mathrm{g}$ of hTERT peptide I540 emulsified in the adjuvant Montanide ISA 51 and delivered subcutaneously in the right thigh (Right). Patients are additionally vaccinated with 10, 100, or $1000 \mu \mathrm{g}$ of CMV peptide N495 (an important control for patient immunological response) in the left thigh (Left). GM-CSF $(70 \mu \mathrm{g} \times 1)$ is given subcutaneously at each peptide injection site. The protocol permits 8 vaccinations over 27 weeks. A minimum of 5 and a maximum of 8 patients will be treated at each of the three dose levels, depending on toxicity, in a standard clinical trial design. The maximum tolerated dose (MTD) will be defined as the highest dose for which fewer than 2 patients develop a significant treatment-related toxicity. Additional patients will be treated at the MTD so that a total of 12 patients will have been treated at the MTD. If 12 patients are treated at the MTD and 8 patients are treated at each of the other two doses, a maximum of 28 patients will be enrolled.

second dose level, no treatment-related serious adverse events have been observed. Injection site reactions and tumor pain following I540 peptide vaccination have occurred (in contrast to our first trial). In one patient, tumor infiltrating lymphocytes associated with marked tumor necrosis have been observed after vaccination (unpublished observations). Based on flow cytometric tetramer analyses, $7-10 \%$ of infiltrating $\mathrm{CD} 8{ }^{+} \mathrm{T}$-cells were specific for hTERT I540 peptide after vaccination and were persistent for $7+$ months (unpublished observations). These results suggest that telomerase can serve as a tumor rejection antigen.

In an ongoing trial at Duke University, 12 patients with hormone-refractory prostate cancer were vaccinated weekly with $1 \times 10^{6}$ DC loaded with RNA encoding a chimeric hTERT/LAMP to allow for simultaneous priming of $\mathrm{CD}^{+}$and CD8 ${ }^{+}$T-cells or DC loaded with hTERT RNA alone. No toxicities have been reported, and induction of both $\mathrm{CD} 4^{+}$and $\mathrm{CD} 8^{+}$T-cells were observed ( $\mathrm{Su}$ et al. 2003a). Higher levels of hTERT-specific $\mathrm{CD}^{+}$T-cells and CTL with higher lytic activity were induced in patients who received DC transfected with chimeric hTERT/ LAMP RNA versus those who received DC with hTERT RNA (Su et al. 2003a). These results suggest that $\mathrm{CD}^{+}$cells augment anti-tumor responses even in the primary response stage and encourage further exploration of simultaneous activation of $\mathrm{CD}^{+}{ }^{+}$and $\mathrm{CD} 8{ }^{+}$T-cells. Interestingly, this same group vaccinated 10 patients with renal cell carcinoma using total tumor RNA ( $\mathrm{Su}$ et al. 2003b). No dose-related toxicities or vaccinerelated side effects, including auto-immunity, were reported, while 6 of 7 patients underwent an expansion of tumor-specific T-lymphocytes. Vaccine-induced CTL were reactive against a variety of renal cell carcinoma antigens, including hTERT.

Another phase I effort in Norway has also attempted to generate both $\mathrm{CD}^{+}$and $\mathrm{CD} 8^{+}$ hTERT-specific T-cells. A total of 505 vaccinations were given to 77 patients with non-resectable pancreatic cancer (47 patients), malignant melanoma (10 patients), and non-small cell lung cancer (20 patients). No serious adverse events and a correlation between vaccine dose, number of responders, and survival in pancreatic cancer patients was reported (Gaudernack et al. 2003).

Overall, these five studies present promise for the future of hTERT as a target for universal cancer immunotherapy. Low toxicities with data suggesting the potential for causing tumor regression support the rationale of hTERT as a tumor rejection antigen. Phase II clinical trials are currently being conducted to better ascertain the effectiveness of using hTERT to cause tumor death and regression. 


\section{Summary}

The future for hTERT as a universal tumor rejection antigen looks bright. In vitro and in vivo work demonstrates that hTERT meets all the criteria of a tumor associated antigen: widely expressed in a tumor-specific manner, naturally and effectively processed and presented antigens in the context of MHC class I molecules, and recognition by the available $\mathrm{T}$-cell repertoire present in both normal and cancer patients. Additionally, hTERT's role in preventing tumor cell senescence suggests malignancies would be unable to downregulate hTERT expression or telomerase activity in response to the selective pressure of hTERT based immunotherapy. The presence of numerous dominant and variant cryptic epitopes of different HLA alleles that are capable of inducing CTL and CD4 ${ }^{+}$T-lymphocytes provide several options for vaccine-based therapy and potential for future epitope discovery. Completed and ongoing clinical trials have demonstrated that hTERT-specific CTL alone as well as in combination with hTERTspecific $\mathrm{CD}^{+}{ }^{+}$lymphocytes can be generated via a cancer vaccine approach with no serious autoimmune or toxic side effects, including bone marrow and immune function. While hTERTs effectiveness in inducing tumor regression will be further assessed in phase II clinical trials, initial results from phase I trials suggests that regression and rejection is possible due to the observation of tumor necrosis associated with the presence of tumor infiltrating lymphocytes in some patients.

\section{References}

Arai J., Yasukawa M., Ohminami H., Kakimoto M., Hasegawa A. and Fujita S. 2001. Identification of human telomerase reverse transcriptase-derived peptides that induce HLA-A24restricted antileukemia cytotoxic T lymphocytes. Blood 97: 2903-2907.

Ayyoub M., Migliaccio M., Guillaume P., Lienard D., Cerottini J.C., Romero P., Levy F., Speiser D.E. and Valmori D. 2001. Lack of tumor recognition by hTERT peptide 540-548-specific $\mathrm{CD} 8(+) \mathrm{T}$ cells from melanoma patients reveals inefficient antigen processing. Eur. J. Immunol. 31: 2642-2651.

Broccoli D., Young J.W. and de Lange T. 1995. Telomerase activity in normal and malignant hematopoietic cells. Proc. Natl. Acad. Sci. USA 92: 9082-9086.

Bodnar A.G., Ouellette M., Frolkis M., Holt S.E., Chiu C.P., Morin G.B., Harley C.B., Shay J.W., Lichtsteiner S. and Wright W.E. 1998. Extension of life-span by introduction of telomerase into normal human cells. Science 279: 349-352.
Counter C.M., Avilion A.A., LeFeuvre C.E., Stewart N.G., Greider C.W., Harley C.B. and Bacchetti S. 1992. Telomere shortening associated with chromosome instability is arrested in immortal cells which express telomerase activity. EMBO J 11: 1921-1929.

Counter C.M., Botelho F.M., Wang P., Harley C.B. and Bacchetti S. 1994. Stabilization of short telomeres and telomerase activity accompany immortalization of Epstein-Barr virustransformed human B lymphocytes. J. Virol. 68: 3410-3414.

Counter C.M., Meyerson M., Eaton E.N., Ellisen L.W., Caddle S.D., Haber D.A. and Weinberg R.A. 1998. Telomerase activity is restored in human cells by ectopic expression of hTERT (hEST2), the catalytic subunit of telomerase. Oncogene 16: 1217-1222.

Gaudernack G., Buanes T., Meo M., Aamdal S., Brunsvig P., Braathen L.R., Kernland K., Gjertsen M.K., Eriksen J.A. and Moller M. 2003. Clinical trials of a peptide based vaccine targeting telomerase. Proc. Am. Soc. Clin. Oncol. 22: 166.

Gilboa E. 1999. The makings of a tumor rejection antigen. Immunity 11: 263-70.

Gross D.A., Graff-Dubois S., Opolon P., Cornet S., Alves P., Bennaceur-Griscelli A., Faure O., Guillaume P., Firat H., Chouaib S., Lemonnier F.A., Davoust J., Miconnet I., Vonderheide R.H. and Kosmatopoulos K. 2004. High vaccination efficiency of low-affinity epitopes in antitumor immunotherapy. J. Clin. Invest. 113: 425-433.

Hahn W.C., Counter C.M., Lundberg A.S., Beijersbergen R.L., Brooks M.W. and Weinberg R.A. 1999a. Creation of human tumour cells with defined genetic elements. Nature 400: 464468.

Hahn W.C., Stewart S.A., Brooks M.W., York S.G., Eaton E., Kurachi A., Beijersbergen R.L., Knoll J.H., Meyerson M. and Weinberg R.A. 1999b. Inhibition of telomerase limits the growth of human cancer cells. Nat. Med. 5: 1164-1170.

Harle-Bachor C. and Boukamp P. 1996. Telomerase activity in the regenerative basal layer of the epidermis in human skin and in immortal and carcinoma-derived skin keratinocytes. Proc. Natl. Acad. Sci. USA 93: 6476-6481.

Harley C.B., Kim N.W., Prowse K.R., Weinrich S.L., Hirsch K.S., West M.D., Bacchetti S., Hirte H.W., Counter C.M. and Greider C.W. et al 1994. Telomerase, cell immortality, and cancer. Cold Spring Harb. Symp. Quant. Biol. 59: 307-315.

Harrington L., Zhou W., McPhail T., Oulton R., Yeung D.S., Mar V., Bass M.B. and Robinson M.O. 1997. Human telomerase contains evolutionarily conserved catalytic and structural subunits. Genes Dev. 11: 3109-3115.

Heiser A., Maurice M.A., Yancey D.R., Coleman D.M., Dahm P. and Vieweg J. 2001a. Human dendritic cells transfected with renal tumor RNA stimulate polyclonal T-cell responses against antigens expressed by primary and metastatic tumors. Cancer Res. 61: 3388-3393.

Heiser A., Maurice M.A., Yancey D.R., Wu N.Z., Dahm P., Pruitt S.K., Boczkowski D., Nair S.K., Ballo M.S., Gilboa E. and Vieweg J. 2001b. Induction of polyclonal prostate cancer-specific CTL using dendritic cells transfected with amplified tumor RNA. J. Immunol. 166: 2953-2960.

Herbert B., Pitts A.E., Baker S.I., Hamilton S.E., Wright W.E., Shay J.W. and Corey D.R. 1999. Inhibition of human telomerase in immortal human cells leads to progressive telomere shortening and cell death. Proc. Natl. Acad. Sci. USA 96: 14276-14281. 
Hiyama K., Hirai Y., Kyoizumi S., Akiyama M., Hiyama E., Piatyszek M.A., Shay J.W., Ishioka S. and Yamakido M. 1995. Activation of telomerase in human lymphocytes and hematopoietic progenitor cells. J. Immunol. 155: 3711-3715.

Hung K., Hayashi R., Lafond-Walker A., Lowenstein C., Pardoll D. and Levitsky H. 1998. The central role of CD4(+) $\mathrm{T}$ cells in the antitumor immune response. J. Exp. Med. 188: 2357-2368.

Janssen E.M., Lemmens E.E., Wolfe T., Christen U., von Herrath M.G. and Schoenberger S.P. 2003. CD4 + T cells are required for secondary expansion and memory in $\mathrm{CD} 8+\mathrm{T}$ lymphocytes. Nature 421: 852-856.

Kim N.W., Piatyszek M.A., Prowse K.R., Harley C.B., West M.D., Ho P.L., Coviello G.M., Wright W.E., Weinrich S.L. and Shay J.W. 1994. Specific association of human telomerase activity with immortal cells and cancer. Science 266: 2011-2015.

Lev A., Denkberg G., Cohen C.J., Tzukerman M., Skorecki K.L., Chames P., Hoogenboom H.R. and Reiter Y. 2002. Isolation and characterization of human recombinant antibodies endowed with the antigen-specific, major histocompatability complex-restricted specificity of $\mathrm{T}$ cells directed toward the widely expressed tumor T-cell epitopes of the telomerase catalytic subunit. Cancer Res. 62: 3184-3194.

Masutomi K., Yu E.Y., Khurts S., Ben-Porath I., Currier J.L., Metz G.B., Brooks M.W., Kaneko S., Murakami S., DeCaprio J.A., Weinberg R.A., Stewart S.A. and Hahn W.C. 2003. Telomerase maintains telomere structure in normal human cells. Cell 114: 241-253.

Meyerson M., Counter C.M., Eaton E.N., Ellisen L.W., Steiner P., Caddle S.D., Ziaugra L., Beijersbergen R.L., Davidoff M.J., Liu Q., Bacchetti S., Haber D.A. and Weinberg R.A. 1997. hEST2, the putative human telomerase catalytic subunit gene, is up-regulated in tumor cells and during immortalization. Cell 90: 785-795.

Minev B., Hipp J., Firat H., Schmidt J.D., Langlade-Demoyen P. and Zanetti M. 2000. Cytotoxic T cell immunity against telomerase reverse transcriptase in humans. Proc. Natl. Acad. Sci. USA 97: 4796-4801.

Nair S.K., Heiser A., Boczkowski D., Majumdar A., Naoe M., Lebkowski J.S., Vieweg J. and Gilboa E. 2000. Induction of cytotoxic $\mathrm{T}$ cell responses and tumor immunity against unrelated tumors using telomerase reverse transcriptase RNA transfected dendritic cells. Nat. Med. 6: 1011-1017.

Nakamura T.M., Morin G.B., Chapman K.B., Weinrich S.L., Andrews W.H., Lingner J., Harley C.B. and Cech T.R. 1997. Telomerase catalytic subunit homologs from fission yeast and human. Science 277: 955-959.

Ramakrishnan S., Eppenberger U., Mueller H., Shinkai Y. and Narayanan R. 1998. Expression profile of the putative catalytic subunit of the telomerase gene. Cancer Res. 58: 622-625.

Rosenberg S.A. 1997. Cancer vaccines based on the identification of genes encoding cancer regression antigens. Immunol. Today 18: 175-182.

Rosenberg S.A. 2001. Progress in human tumour immunology and immunotherapy. Nature 411: 380-384.

Scardino A., Gross D.A., Alves P., Schultze J.L., Graff-Dubois S., Faure O., Tourdot S., Chouaib S., Nadler L.M., Lemonnier F.A., Vonderheide R.H., Cardoso A.A. and Kosmatopoulos K. 2002. HER-2/neu and hTERT cryptic epitopes as novel targets for broad spectrum tumor immunotherapy. J. Immunol. 168: 5900-5906.

Schroers R., Huang X.F., Hammer J., Zhang J. and Chen S.Y. 2002. Identification of HLA DR7-restricted epitopes from human telomerase reverse transcriptase recognized by CD4+ T-helper cells. Cancer Res. 62: 2600-2605.

Schroers R., Shen L., Rollins L., Rooney C.M., Slawin K., Sonderstrup G., Huang X.F. and Chen S.Y. 2003. Human telomerase reverse transcriptase-specific T-helper responses induced by promiscuous major histocompatability complex class II-restricted epitopes. Clin. Cancer Res. 9: 4743-4755.

Schultze J.L. and Vonderheide R.H. 2001. From cancer genomics to cancer immunotherapy: toward second-generation tumor antigens. Trends Immunol. 22: 516-523.

Speiser D.E., Cerottini J.C. and Romero P. 2002. Can hTERT peptide (540-548)-specific CD8 T cells recognize and kill tumor cells? Cancer Immun. 2: 14.

Su Z., Dannull J., Dahm P., Yang B., Coleman D., Yancey D., Sichi S., Higgins J., Gilboa E. and Vieweg J. 2003a. Vaccination of patients with hormone-refractory prostate cancer using telomerase RNA transfected DC: results from a phase I clinical trial. Blood 102S: 11.

Su Z., Dannull J., Heiser A., Yancey D., Pruitt S., Madden J., Coleman D., Niedzwiecki D., Gilboa E. and Vieweg J. 2003b. Immunological and clinical responses in metastatic renal cancer patients vaccinated with tumor RNA-transfected dendritic cells. Cancer Res. 63: 2127-2133.

Van den Eynde B.J. and van der Bruggen P. 1997. T cell defined tumor antigens. Curr. Opin. Immunol. 9: 684-693.

Van Pel A., van der Bruggen P., Coulie P.G., Brichard V.G., Lethe B., van den Eynde B., Uyttenhove C., Renauld J.C. and Boon T. 1995. Genes coding for tumor antigens recognized by cytolytic T lymphocytes. Immunol. Rev. 145: 229250

Vaziri H. and Benchimol S. 1998. Reconstitution of telomerase activity in normal human cells leads to elongation of telomeres and extended replicative life span. Curr. Biol. 8: 279-382.

Vonderheide R.H., Hahn W.C., Schultze J.L. and Nadler L.M. 1999. The telomerase catalytic subunit is a widely expressed tumor-associated antigen recognized by cytotoxic $\mathrm{T}$ lymphocytes. Immunity 10: 673-679.

Vonderheide R.H., Anderson K.S., Hahn W.C., Butler M.O., Schultze J.L. and Nadler L.M. 2001b. Characterization of HLA-A3-restricted cytotoxic $\mathrm{T}$ lymphocytes reactive against the widely expressed tumor antigen telomerase. Clin. Cancer Res. 7: 3343-3348.

Vonderheide R.H., Domchek S.M., Schultze J.L., George D.J., Hoar K.M., Chen D.Y., Stephans K.F., Masutomi K., Loda M., Xia Z., Anderson K.S., Hahn W.C. and Nadler L.M. 2004. Vaccination of cancer patients against telomerase induces functional antitumor $\mathrm{CD} 8+\mathrm{T}$ lymphocytes. Clin. Cancer Res. 10: 828-839.

Vonderheide R.H., Schultze J.L., Anderson K.S., Maecker B., Butler M.O., Xia Z., Kuroda M.J., von Bergwelt-Baildon M.S., Bedor M.M., Hoar K.M., Schnipper D.R., Brooks M.W., Letvin N.L., Stephans K.F., Wucherpgennig K.W., Hahn W.C. and Nadler L.M. 2001a. Equivalent induction of telomerase-specific cytotoxic $\mathrm{T}$ lymphocytes from tumorbearing patients and healthy individuals. Cancer Res. 61: 8366-8370. 
Yasumoto S., Kunimura C., Kikuchi K., Tahara H., Ohji H., Yamamoto H., Ide T. and Utakoji T. 1996. Telomerase activity in normal human epithelial cells. Oncogene 13: 433-439.
Zhang X., Mar V., Zhou W., Harrington L. and Robinson M.O. 1999. Telomere shortening and apoptosis in telomere-inhibited human tumor cells. Genes Dev. 13: 2388-2399. 